\title{
Intraoperative Radiotherapy (IORT) with 50-kV X-Ray Machines as Boost in Breast Cancer - More Questions than Answers
}

\author{
Vratislav Strnad \\ Strahlenklinik, Universitätsklinikum Erlangen, Germany
}

In the treatment of breast cancer in early stages breast conserving therapy is a generally accepted treatment philosophy. Local control and survival data are the same as after mastectomy. The additional aim of breast conserving therapy is to treat patients with breast cancer without mutilation and simultaneously with optimal cosmetic results, as far as possible. Radiation therapy to the whole breast after breast conserving surgery is the standard treatment in the conservative approach and its value has been established in many retrospective studies as well as prospective randomised trials. The hazard ratio calculated according to the largest studies indicates a reduction of local failures after radiation therapy by a factor of 4 in comparison to not irradiated cohorts [1-6]. Randomised trials have recently confirmed older data, showing that a clear doseresponse relationship for local control exists. A dose increase of $15 \mathrm{~Gy}$ as boost (after $50 \mathrm{~Gy}$ postoperative whole breast irradiation) reduces the local recurrence rates by about one half [7]. On the other hand, cosmetic outcome is inversely related to radiation dose and volume of reference isodose. It is indisputable that incomplete tumour resection results in a very high risk of local recurrence and is undoubtedly an indication for a boost with $20 \mathrm{~Gy}$.

In patients with complete resection the indication for boost irradiation is more complex. Recently 3 randomized trials using boost irradiation [8-10] reported about increased local control rates in some subgroups of breast cancer patients. The published EORTC data deal with results on patients with negative margins only. A 16 Gy boost in addition to $50 \mathrm{~Gy}$ whole breast radiotherapy significantly reduced the annual odds of local recurrence by $41 \%$; the benefit was verifiable only in patients aged 50 years and younger [8]. The main prognostic parameters in Romestaign's data [9] are the positive resection margins, presence of an EIC (extensive intraductal component), tumour size and age.

Based on these facts and data from further pathological stud- ies [11-15] we reach our goal - if we want to compare intraoperative radiotherapy (IORT) using a $50-\mathrm{kV}$ x-ray machine with other techniques for boost irradiation, first of all we have to know is the size of our target volume, second the form of our target volume, also in respect to the distances (relations) to the skin, and third we need to know if this technique is able to give a sufficient dose to the target.

Regarding the first question, it is a well known fact that the risk of remaining microscopic disease depends on the resection margins. The larger the resection margins, the less likely are tumour foci in the remaining breast tissue and the smaller can be the 'safety margin' which has to be irradiated. Data from Holland $[11,12]$ suggest that margins of $2-3 \mathrm{~cm}$ from the tumour borders should be covered by the surgical resection margin and the 'radiotherapeutic safety margin'. In the EORTC boost trial, a safety margin of $1.5 \mathrm{~cm}$ breast tissue after complete and $3 \mathrm{~cm}$ after incomplete resection was used. Regarding the second and third question it is obvious that only in rare cases it is possible for the surgeon to guarantee the same resection margins in all directions. Therefore, most often the radiation oncologist has to resolve the situation: for example in the direction 'skin' the resection margin is $>10$ $\mathrm{mm}$, in the direction 'thoracic wall' it is $<2 \mathrm{~mm}$ (and also the intact fascia was resected), cranial $5 \mathrm{~mm}$, lateral $>10 \mathrm{~mm}$, medial only $1 \mathrm{~mm}$ and caudal $2 \mathrm{~mm}$. The job of the radiation oncologist in a such situations is to choose an appropriate boost technique, which allows to give a sufficient dose of $20 \mathrm{~Gy}$ (or in case of resection margins $>2 \mathrm{~mm} 16 \mathrm{~Gy}$ ) in appropriate distances from the tumour bed (addition of 'radiotherapeutic safety margins' and of surgical resection margins must be in all directions $2 \mathrm{~cm}$ at least, better $3 \mathrm{~cm}$ ) and simultaneously respecting that the skin (at least $5 \mathrm{~mm}$ thickness) and the thoracic wall are not part of the clinical target volume.

In principle the radiation oncologist has 3 techniques for the delivery of the boost dose: electron beams, interstitial multi-

\begin{tabular}{ll}
\hline KARGER & @ 2006 S. Karger GmbH, Freiburg \\
Fax +49 7614520714 & Accessible online at: \\
$\begin{array}{l}\text { E-mail Information@Karger.de } \\
\text { www.karger.com }\end{array}$ & www.karger.com/onk
\end{tabular}


catheter brachytherapy or recently as experimental treatment modality also intraoperative radiotherapy, using a $50-\mathrm{kV}$ x-ray machine. The boost method using electron beams is associated with larger treatment volumes resulting in a higher rate of breast fibroses and also of telangiectasia due the higher skin dose, but using this method there are no problems to sufficiently cover the different 'radiotherapeutic safety margins' in all directions. Therefore the boost with electron beams should be performed particularly in superficial and peripheral localisations of the tumour bed. Interstitial brachytherapy is a treatment method which makes it possible to deliver high radiation doses precisely to volumes confined to the tumour bed respecting the different surgical resection margins in different directions and also different sizes of the tumour. Simultaneously it is very sparing with respect to surrounding tissues, including the overlying skin [16-20]. However, the technical performance of brachytherapy and also the physician's skill and experience are critical, and so it is very important to strictly respect the expert's recommendations for this treatment method $[16-18,20]$. As well for boost using the electron beam as for boost using interstitial brachytherapy the delivery of sufficient doses $\geq 16$ Gy is unproblematic.

The boost method using IORT with a $50-\mathrm{kV}$ x-ray machine (Intrabeam ${ }^{\mathrm{TM}}$ ) confronts us with some serious problems. The first results of this method are described by Kraus-Tiefenbacher et al. [21] in this issue. The authors report here early experiences and conclude that after 46 Gy postoperative whole breast irradiation the IORT with $20 \mathrm{~Gy}$, prescribed to the applicator surface as a boost, results in low acute toxicity. Before adapting this treatment policy inside as well as outside of clinical trials, one has to question the safety of this approach not only regarding the probability of side effects but in particular regarding local recurrence rates.
Let us start with above-mentioned fact that margins of $2-3 \mathrm{~cm}$ from the tumour should be covered as addition of surgical resection margin and 'radiotherapeutic safety margin'. Unfortunately, Kraus-Tiefenbacher et al. did not present any data about the size of resection margins. Certainly it has to be assumed that not all reported patients had resection margins of at least $2 \mathrm{~cm}$ in all directions. Consequently this typical clinical situation represents the central problem, because IORT with a $50-\mathrm{kV}$ x-ray machine allows to give a sufficient boost dose (equivalent to 16 or $20 \mathrm{~Gy}$ ) only in a tissue depth of some millimetres; already in a depth of $10 \mathrm{~mm}$ from the applicator surface an insufficient dose of only 5 Gy (equivalent to approximately $7.5-10$ Gy of electron beam) is delivered. As a consequence we can postulate that IORT boost with a $50-\mathrm{kV}$ $\mathrm{X}$-ray machine might only be accepted if resection margins $>2 \mathrm{~cm}$, better $>3 \mathrm{~cm}$, in all 6 directions can be guaranteed. It is of course evident that it is very difficult, if not impossible, to fulfil and confirm this condition at the time of breast conserving surgery. But this claim is also important because of the second fact: the $50-\mathrm{kV}$ x-ray machine allows only a ball-shaped form of the isodoses, therefore it is not possible for IORT to respect the different resection margins in all directions.

In summary, despite acceptable short-term results regarding the tolerance of IORT with a 50-kV x-ray machine, one should interpret the presented results with extreme caution, as they are preliminary data and some important data are missing. Consequently, the boost irradiation using IORT with the $50-\mathrm{kV}$ x-ray machine should not be applied in routine clinical practice, and should be tested only in well defined clinical studies with strict inclusion criteria, particularly respecting the necessity of knowledge of resection margins at the time of IORT. Otherwise the risk that the boost irradiation using IORT by 'high risk' patients will result in a high breast recurrence rate is high.

\section{References}

1 Clark RM, Whelan T, Levine M, Roberts R, Willan A, McCulloch P, Lipa M, Wilkinson RH, Mahoney $\mathrm{LJ}$ : Randomized clinical trial of breast irradiation following lumpectomy and axillary dissection for node-negative breast cancer: an update. Ontario Clinical Oncology Group. J Natl Cancer Inst 1996; 88:1659-1664.

2 Fisher B, Anderson S, Redmond CK, Wolmark N, Wickerham DL, Cronin WM: Reanalysis and results after 12 years of follow-up in a randomized clinical trial comparing total mastectomy with lumpectomy with or without irradiation in the treatment of breast cancer. N Engl J Med 1995;333: 1456-1461.

3 Forrest AP, Stewart HJ, Everington D, Prescott RJ, McArdle CS, Harnett AN, Smith DC, George WD: Randomised controlled trial of conservation therapy for breast cancer: 6-year analysis of the Scottish trial. Scottish Cancer Trials Breast Group. Lancet 1996;348:708-713.

4 Kurtz JM: Recurrence in the Conserved Breast: Why all this fuss about risk factors? Eur J Cancer 1999;35:1752-1754.
5 Liljegren G, Holmberg L, Bergh J, Lindgren A, Tabar L, Nordgren H, Adami HO: 10-Year results after sector resection with or without postoperative radiotherapy for stage I breast cancer: a randomized trial. J Clin Oncol. 1999;17:2326-2333.

6 Veronesi U, Marubini E, Mariani L, Galimberti V, Luini A, Veronesi P, Salvadori B, Zucali R: Radiotherapy after breast-conserving surgery in small breast carcinoma: long-term results of a randomized trial. Ann Oncol. 2001;12:997-1003.

7 Van Limbergen E, Van den Bogaert W, Van der Schueren E, Rijnders A: Tumour excision and radiotherapy as primary treatment of breast cancer. Analysis of patient and treatment parameters and local control. Radiother Oncol 1987;8:1-9.

8 Bartelink H, Horiot JC, Poortmans P, Struikmans H, Van den Bogaert W, Barillot I, Fourquet A, Borger J, Jager J, Hoogenraad W, Collette L, Pierart M; European Organization for Research and Treatment of Cancer Radiotherapy and Breast Cancer Groups: Recurrence rates after treatment of breast cancer with standard radiotherapy with or without additional radiation. N Engl J Med 2001; 345:1378-1387
9 Romestaing P, Lehingue Y, Carrie C, Coquard R, Montbarbon X, Ardiet JM, Mamelle N, Gerard JP: Role of a 10-Gy boost in the conservative treatment of early breast cancer: results of a randomized clinical trial in Lyon, France. J Clin Onco 1997;15:963-968.

10 Teisseir E: Boost in conservative treatment: 6 years results of a randomized trial. Breast Cancer Res Treat 1998;50:245.

11 Faverly DR, Hendriks JH, Holland R: Breast carcinomas of limited extent: frequency, radiologicpathologic characteristics, and surgical margin requirements. Cancer 2001;91:647-659.

12 Holland R, Connolly JL, Gelman R, Mravunac M, Hendriks JHCL, Verbeek ALM, et al.: The presence of an intraductal component following a limited excision correlates with prominent residual disease in the remainder of the breast. J Clin Oncol 1990;8:113-118.

13 Ishida T, Furuta A, Moriya T, Ohuchi N: Pathological assessment of intraductal spread relation to surgical margin state in breast-conserving. Jpn J Clin Oncol 2003;33:161-166. 
14 Ohtake T, Abe R, Kimijima I, Fukushima T, Tsuchiya A, Hoshi K, Wakasa H: Intraductal extension of primary invasive breast carcinoma treated by breast-conservative surgery. Computer graphic three-dimensional reconstruction of the mammary duct-lobular systems. Cancer 1995;76:32-45.

15 Vicini FA, Goldstein NS, Pass H, Kestin LL: Use of pathologic factors to assist in establishing adequacy of excision before radiotherapy in patients treated with breast-conserving therapy. Int J Radiat Oncol Biol Phys 2004;60:86-94.

16 Georg P, Georg D, Van Limbergen E: The use of the source-skin distance measuring bridge indeed reduces skin teleangiectasia after interstitial boost in breast conserving therapy. Radiother Oncol 2005; 7:323-330.

17 Hammer J, Mazeron JJ, Van Limbergen E: Breast boost-why, how, when...? Strahlenther Onkol 1999;175:478-483.

18 Hammer J, Strnad V: Mammakarzinom; in Strnad V, Pötter R, Kovács G (eds): Stand und Perspektiven der klinischen Brachytherapie. Uni-Med, Hamburg, 2004, pp 157-167.

-19 Resch A, Potter R, Van Limbergen E, Biber E, Klein T, Fellner C, Handl-Zeller L, Langbauer G, Schurer-Waldheim H, Staffen A, Jakesz R, Kubista E, Lehr S, Seitz W: Long-term results (10 years) of intensive breast conserving therapy including a high-dose and large-volume interstitial brachytherapy boost (LDR/HDR) for T1/T2 breast cancer. Radiother Oncol 2002:63:47-58.

20 Van Limbergen E: Indications and technical aspects of brachytherapy in breast conserving treatment of breast cancer. Cancer Radiother 2003;7: 107-120.

21 Kraus-Tiefenbacher U, Bauer L, Kehrer T, Hermann B, Melchert F, Wenz F: Intraoperative radiotherapy (IORT) as a boost in patients with early stage breast cancer - acute toxicity. Onkologie 2006;29:77-82. 